Yu Meng, Hongbin Gu* and Xinyu Zhang

\title{
Experimental Study of Kerosene Ignition and Flame Stabilization in a Supersonic Combustor
}

https://doi.org/10.1515/tij-2019-0026

Received August 21, 2019; accepted August 29, 2019

\begin{abstract}
A supersonic kerosene ignition and flame stabilization experiments were conducted on a directly connected supersonic combustion test bench. The kerosene fuel was jetted by wall jet at Ma 2.5 airflow. High-speed photography was used to record the $\mathrm{CH}^{\star}$ emission during ignition, extinguishing and evolution of the flame. Experiments of different equivalence ratios were performed. The processes of ignition, flame holding, and extinguishing were observed as well. The experiment showed the characteristics of ignition core initiation and extension. The time of ignition increased with the increase of equivalence ratios. Flame stability during the process of Ma 2.5 at the entrance of the combustion chamber was also studied. An equilibrium flame pattern of shock wave and flame was discovered in the experiment. In the stable flame state, shock waves near the kerosene jet orifice promote atomization and blending, and the combustion chamber pressure with stable flame makes the shock waves stable near the kerosene jet orifice, thus forming the flame stability model. The whole process and characteristics of kerosene ignition, flame holding and extinguishing are revealed in the experiment.
\end{abstract}

Keywords: scramjet, supersonic combustion, ignition, flame stability, extinguishing

PACS $^{\circledR}$ (2010). 47.70.Pq

\section{Introduction}

The scramjet has a simple structure, no rotating parts, no need to carry oxidant, and a larger specific impulse

*Corresponding author: Hongbin Gu, Institute of Mechanics CAS, Beijing 100190, China, E-mail: guhb@imech.ac.cn

Yu Meng, School of Engineering Science, University of Chinese Academy of Sciences, Beijing 100049, China,

E-mail: mengyu92@foxmail.com

Xinyu Zhang, Institute of Mechanics CAS, Beijing 100190, China,

E-mail: changxy@imech.ac.cn compared with rocket and turbine engines. Additionally, an aircraft fitted with scramjet can fly at higher altitudes than which fitted turbine engines. The supersonic combustor is one of the key propulsion system components of air-breathing supersonic flow over cavities; it has been extensively studied for many years because of its relevance to hypersonic vehicle aerodynamic configurations [1], and its ignition performance and heat release distribution are critical parameters for evaluation and optimization of engine performance [2]. Flame stability is an important factor to be addressed in the design of an injection system. Combustion instability often occurs in ramjets and similar jets and has a large impact on the performance and reliability of the propulsion system [3].

In the 1990s, the cavity has been first used as a flame stabilizer [4]. Sun studied the mechanism of flame stability in the cavity and concluded that triple flame theory might be the basic flame stability mechanism for cavity flame holders [5]. Much research has been performed on the ignition and flame spread of these engines. The ignition of fuel can be divided into three stages [6]. (1) The formation of the initial fire core. The initial fire core will be formed when the fuel and air mixture in the combustion chamber reaches the ignition condition (high total temperature or forced ignition). (2) The formation of the initial flame. After the formation of the initial core, the fuel around the core is constantly ignited. Under the action of airflow, the initial core expands to the surrounding area to form the initial flame. (3) The expansion and evolution of the initial flame, which eventually forms a stable flame after this stage. The methods of forced ignition are guided flame, spark plug, jet ignition and throttling choking ignition et al.

Daniel and Driscoll [7] conducted an experimental study on the flame-stabilized mode of a dual-mode scramjet with a cavity. In ram-mode, there are two flame-stabilizing modes when the fuel injection position is far from the cavity: the concave flame and the jet wake flame. The wall pressure shows that the concave flame is most stable, and the jet wake is followed by the flame. When the fuel injection position is close to the cavity, a mixed flame mode occurs, and the flame is stabilized in the position 
where the reaction zones overlap in the two flame mode. In the scram-mode, there is only a concave flame mode.

As for study on the mechanism of steady flame mode. In 2001, O'Brien et al. [8] considered the role of limited chemical reaction rates in the analysis of engine performance and gave more accurate results for combustion and heat release distribution. In 2009, Micka et al. [9] analyzed the $\mathrm{HC}^{\star}$ and $\mathrm{CH}^{\star}$ self-luminescence characteristics of a combustion chamber with a wall jet and cavity structure. It is believed that the heat release depends mainly on the flame structure and propagation characteristics. Different flame stability mechanisms lead to significant differences in the heat release distribution.

Huang [10] analyzed various types of flame structures in dual-mode scramjets. The cavity is widely used for flame stabilization in a dual-mode combustor because it offers advantages such as smaller additional drag force and total pressure loss. However, the cavity is limited by the combustor configuration, jet configuration, etc. [1012]. Cai et al. [13] studied the influence of cavity geometry on mixing, flame stability, and ignition.

As for liquid kerosene as supersonic fuel, it can't be ignited by spark, even it can't burn continuously in supersonic flow. Sometimes, the cavity can't hold the kerosene flame in supersonic flow or scram mode. So we add a certain amount of hydrogen for ignition and combustion stabilization. In recent years, many studies about kerosene fuel combustion in supersonic flow has been performed in the way of experience or simulation. Ye Tian et al. [14] studied hydrogen flame stabilization modes in scramjet. Two typical combustion modes have been attained by changing the ER of hydrogen. Furthermore, kerosene fuelled flame structure with different fuel jet points were studied in experiment way as well [15-17].

However, as for kerosene ignition, little research can be found in previous references, especially on the flame shape and propagation instability during flameout, or the heat release area in the cavity during the process of flame out. More importantly, the relationship between flame instability and extinction is an important question with little research. This paper studied the ignition process of hydrogen guided kerosene under different equivalence ratio conditions at Ma 2.5, analyzed the flame propagation instability and flameout phenomenon in the scramjet engine combustion chamber. The mechanism providing a theoretical basis for engine design and control was revealed.

\section{Design and analysis}

\section{Experimental setup}

The experimental study was carried out on the directly connected supersonic combustion test facility in the Institute of Mechanics, CAS. The experimental facility schematic is shown in Figure 1. The source of compressed air is a compressed air tank. Hydrogen fuelled heater was used to heat the air and additional oxygen was added to maintain a $24.5 \% \mathrm{O}_{2}$ mass fraction in the vitiated air, and the mass fraction of $\mathrm{H}_{2} \mathrm{O}$ and $\mathrm{N}_{2}$ were $8.5 \%$, and $67 \%$, respectively. The outlet of the heater is connected to a throat nozzle, accelerating the airflow, and the exit air flow of the nozzle is Ma 2.5, which is the purpose of simulating high-temperature and high-speed airflow.

The combustion chamber structure and fuel injection position is shown in Figure 1. In the flame extinguishing experiments performed in the first cavity, only fuel-jet-1 worked. The observation of $\mathrm{CH}^{\star}$ and schlieren technique was always on the first cavity. The fuel was kerosene at room temperature, ignited by spark on the top wall of the first cavity. The kerosene cannot be ignited by spark directly, so we used pilot hydrogen ignited by spark to ignite the kerosene.

The high-speed camera used in the experiment was a Phantom's V1612. In this study, the shooting frame rate was $20,000 \mathrm{fps}$ and the exposure time was $3 \mu \mathrm{s}$ of $\mathrm{CH}^{\star}$.

The pressure measuring point is on the top wall of the first cavity, and it is collected by the Initium electronic scanning valve ESP pressure module.

Experimental conditions are given in Table 1, where $P_{0}$ is total inlet pressure, and $T_{0}$ is total inlet temperature of the combustor.

The experiment time scale is shown in Figure 2. The heater worked for the whole process, aiming to produce steady supersonic air flow. The spark, hydrogen and

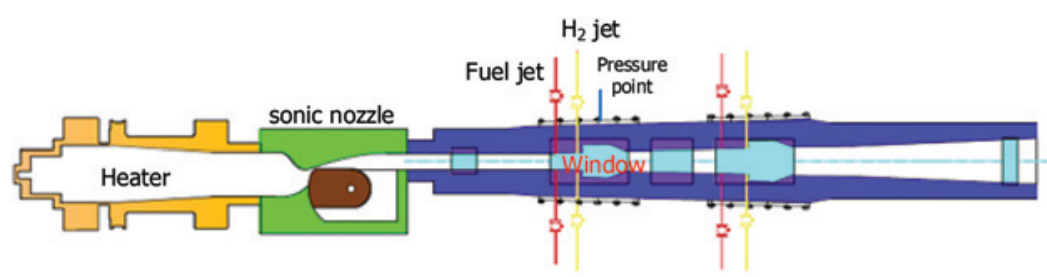

Figure 1: Combustion chamber structure and fuel injection position. 
Table 1: Experimental conditions.

\begin{tabular}{lrrrrrr}
\hline Round & Ma & $\boldsymbol{\Phi}$ & $\boldsymbol{\Phi}(\mathrm{H} 2)$ & $\mathbf{P}_{\mathbf{0}}(\mathrm{MPa})$ & $\mathbf{T}_{\mathbf{0}}(\mathrm{K})$ & $\mathbf{Q}_{\mathbf{0}}(\mathrm{kg} / \mathbf{s})$ \\
\hline R2 & 2.5 & 0.2 & 0.1 & 1.58 & 1216.1 & 1.917 \\
R3 & 2.5 & 0.3 & 0.1 & 1.58 & 1267.8 & 1.905 \\
R4 & 2.5 & 0.35 & 0.1 & 1.58 & 1267.8 & 1.905 \\
\hline
\end{tabular}

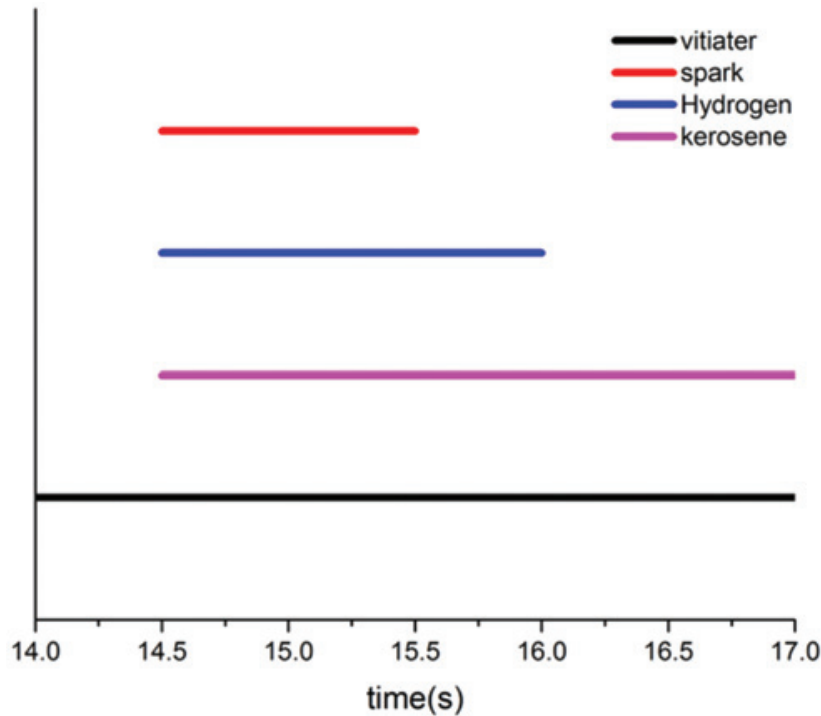

Figure 2: Time scale of the experiment.

kerosene fuel were started at the same time to ignite the supersonic combustor. The spark frequency is approximately $12 \mathrm{~Hz}$, and the energy of every pulse is approximately $14 \mathrm{~J}$. The spark lasts for 1 second and the hydrogen combustion lasts half second longer than the spark. The fuel will last until the flame is extinguished.

\section{Error analysis}

Some physical quantities (such as temperature, pressure, etc.) are direct measurements, and the measurement error depends on sensor accuracy and system random error. Some physical quantities (such as flow rate, heat flow, etc.) are indirect measurements, and the measurement accuracy requires an error transfer function to calculate. If the relation between indirect measurement quantity $y$ and direct measurement quantity $\mathrm{x}_{N}$ is a sum, the error of indirect physical quantity is:

$$
e_{y}=\sqrt{\sum_{1}^{N}\left(\frac{\partial f}{\partial x_{i}}\right)^{2} u_{x_{i}}^{2}}
$$

If the relation between the indirect measurement quantity y and the direct measurement quantity $\mathrm{x}_{N}$ is a multiplication product, the error of the indirect physical quantity is:

$$
e_{y}=\sqrt{\sum_{1}^{N}\left(\frac{\partial \ln f}{\partial x_{i}}\right)^{2} u_{x_{i}}^{2}}
$$

By calculating the above error transfer function, the errors or relative errors of the physical quantities are shown in Table 2.

Table 2: Experimental error.

\begin{tabular}{lrrrrr}
\hline physical quantity & $\mathbf{T}_{\mathbf{0}}$ & $\mathbf{P}_{\mathbf{0}}$ & $\mathbf{P}$ & $\mathbf{\Phi}$ & $\mathbf{Q}_{\mathbf{0}}$ \\
\hline error & $0.5 \%$ & $0.2 \%$ & $0.05 \%$ & $0.1 \%$ & $0.75 \%$ \\
\hline
\end{tabular}

\section{Results and discussion}

\section{Ignition process}

Figures 3-5 show the flame evolution process of hydrogen-guided kerosene fuel ignition under different equivalence ratios in a supersonic combustion chamber. By high-speed photography, a grayscale image of $\mathrm{CH}^{\star}$ illumination is obtained, and the grayscale image is subjected to pseudo color processing to obtain a color image as shown.

As seen from Figure 3, a strong arc forms and a large amount of heat is released, when the spark plug is discharged. The initial fire core propagates to the surroundings after it forms. If the energy lost by the fire core is greater than the energy released by the surrounding fuel during propagation, the initial flame is gradually weakened until it is extinguished, and ignition fails. In contrast, the initial fire core will gradually expand, a stable flame is formed and the ignition is successful.

Obviously, the following conditions was ignited successfully. However, the position closest to the discharge of the spark plug is not ignited, and the starting region of the fire core is in the recirculation zone near the step of the cavity, and it thus gradually expands downstream. The flame kernel expands in the cavity recirculation zone, and finally develops into a shear layer, and forms a typical cavity shaped flame. This is because in the spark plug discharge area, the flow velocity is too fast 


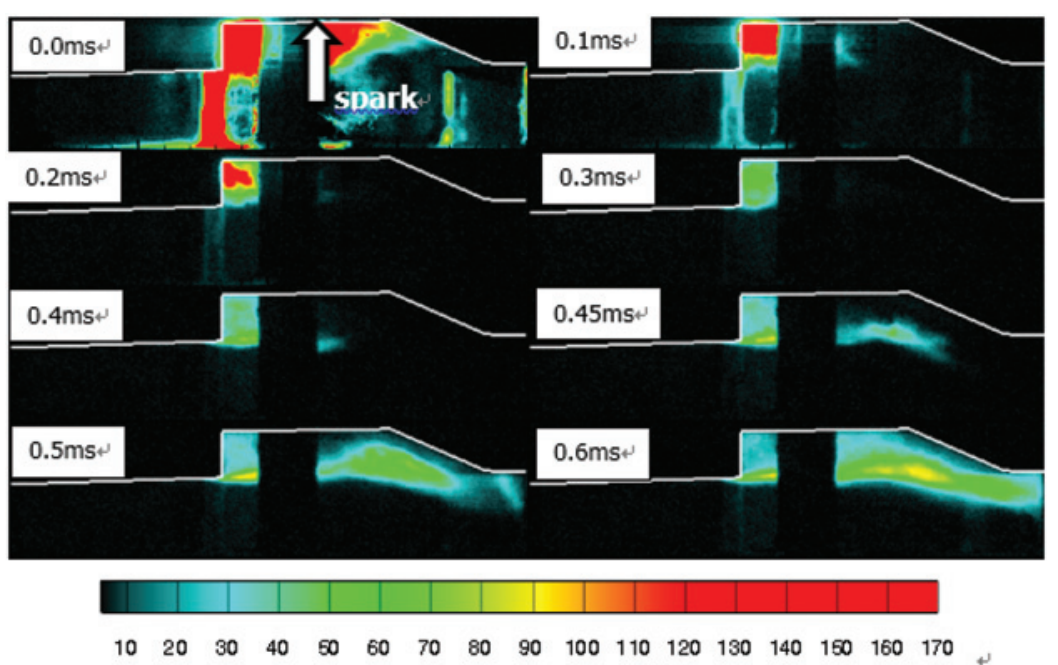

$\begin{array}{lllllllllllllllll}10 & 20 & 30 & 40 & 50 & 60 & 70 & 80 & 90 & 100 & 110 & 120 & 130 & 140 & 160 & 160 & 170\end{array}$

Figure 3: Flame ignition process in case R2.

to form a fire core. At the stepped position of the cavity, the flow velocity is relatively slow due to the airflow forming the recirculation zone. After the nearby fuel is ignited by the arc heat release, the fuel in the recirculation zone is released continuously, and gradually propagates inside the cavity, and finally a stabilized flame is formed in the shear layer.

Compared with the equivalence ratio of 0.2 (Figure 3), the development pattern of the flame did not change significantly, but the $\mathrm{CH}^{\star}$ luminescence intensity is enhanced when the kerosene equivalence ratio increased to 0.3 (Figure 4). Under the conditions of R3, as the use of a flame standard is extended to the shear layer to form a typical flame shape, and the flame expansion time increases by $0.2 \mathrm{~ms}$ compared with the $\mathrm{R} 2$ case.

After the equivalence ratio increased to 0.35 (Figure 5), a typical shear layer flame was formed for up to $1.9 \mathrm{~ms}$.
During the ignition process, there is a tendency for the flame in the recirculation zone to expand toward the inside of the cavity during 0.3 to $0.9 \mathrm{~ms}$. However, a stable cavity flame was not formed, but retracted back to the recirculation zone between 0.9 and $1.4 \mathrm{~ms}$, it re-expanding after $1.4 \mathrm{~ms}$, and finally formed a stable recirculation zone flame at $1.9 \mathrm{~ms}$.

From the ignition speed point of view (Figure 6), the ignition time became longer, with the equivalence ratio increase because kerosene atomization is more difficult under high equivalence ratio conditions, and higher energy is required to achieve a stable flame.

The ignition and flame expansion processes of hydrogen-directed kerosene are similar in different equivalence ratios. The starting position of the fire core is in the recirculation zone at the cavity step, then gradually expands into the interior of the cavity, and finally extends to the

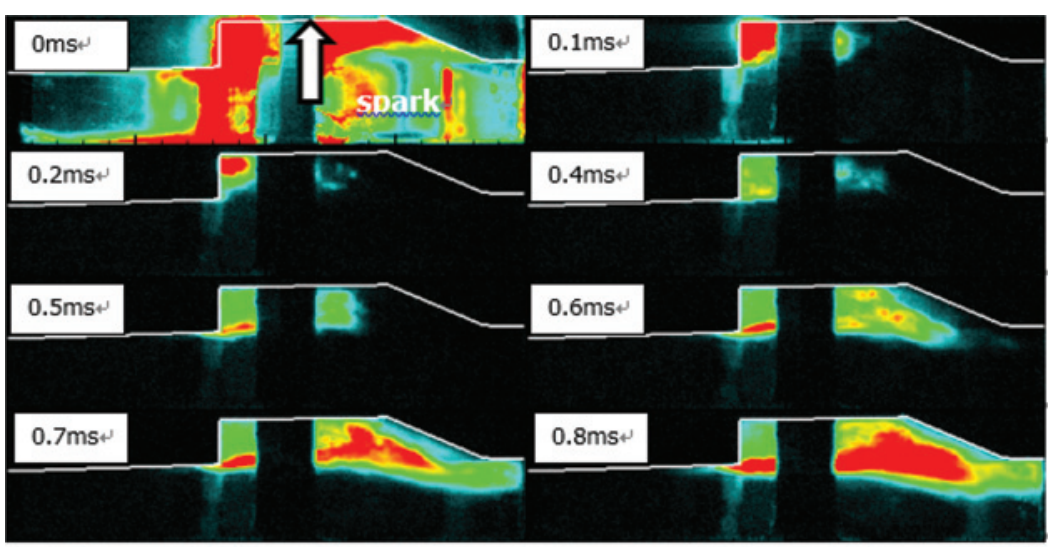

$\begin{array}{lllllllllllllllll}10 & 20 & 30 & 40 & 50 & 60 & 70 & 80 & 90 & 100 & 110 & 120 & 130 & 140 & 150 & 160 & 170\end{array}$

Figure 4: Flame ignition process in case R3. 


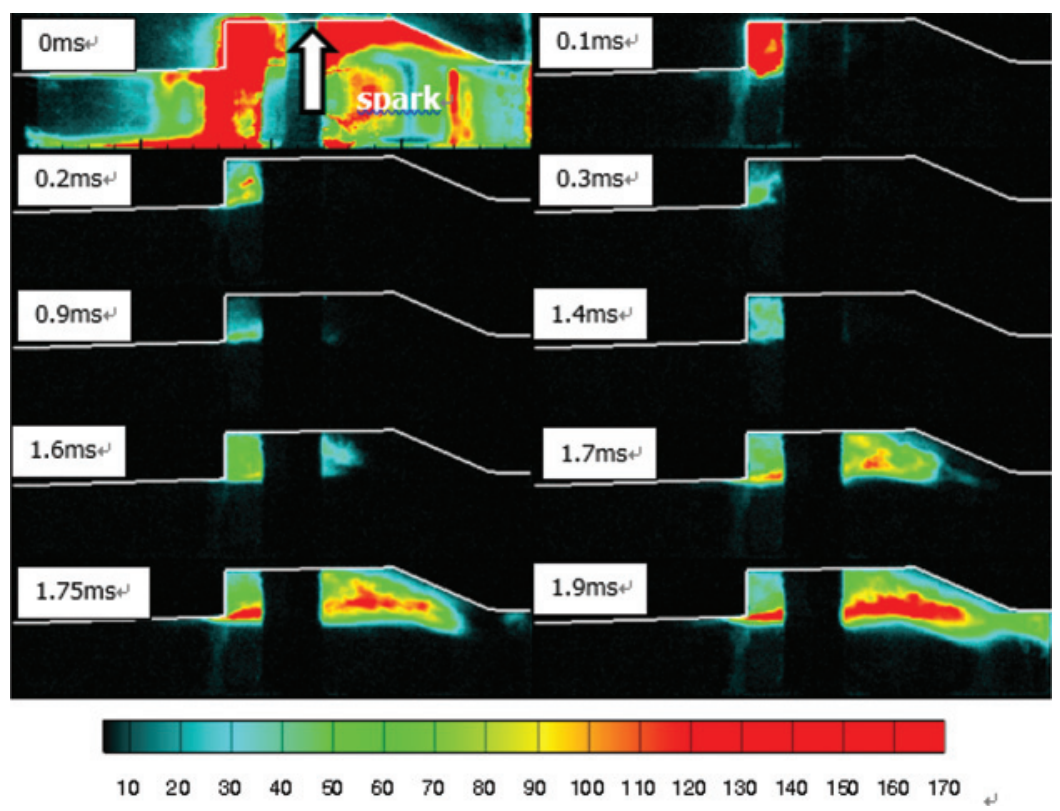

Figure 5: Flame ignition process in case R4.

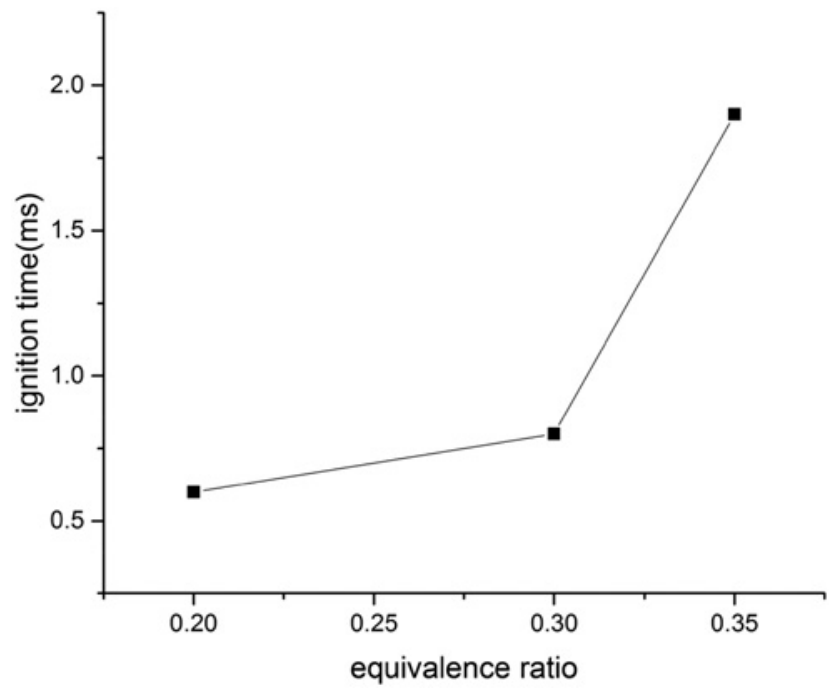

Figure 6: Ignition time varies with equivalence ratio.

recirculation zone to form a stable shear layer flame. This is different from ethylene ignition fire core expansion. The starting position of ethylene fuel ignition is near the spark plug and gradually spreads to the entire cavity [2]. During the flame expansion process, one or more flame cores may form inside the cavity, such as the $0.45 \mathrm{~ms}$ in case $\mathrm{R} 2$ and the $0.6 \mathrm{~ms}$ in case $\mathrm{R} 3$, such as the $0.45 \mathrm{~ms}$ in case $\mathrm{R} 2$ and the $0.6 \mathrm{~ms}$ in case R3. However, this phenomenon is an unstable flame form. There is a high probability that they will not ignite or re-expand from the fire core if multiple flame cores are not ultimately connected in a single-connected singlecore flame configuration. However, with the rapid release of hydrogen, hydrogen-directed liquid kerosene is more likely to form a stable flame than pure liquid kerosene.

\section{Flame stability process}

Flame stability is a very difficult process during supersonic combustion and is closely related to flow fields, shock waves and flame morphology. Additionally, the liquid kerosene flame is very difficult to stabilize in supersonic flow field, due to its slow atomization speed.

As shown in Figure 7. One typical form of flame stabilization is an equilibrium state created by the interaction between a flame and a shock wave. As shown, there is a shock wave that coincides with the starting position and the angle of the flame, and this shock wave has special significance for flame stability. The presence of shock waves makes the flow field more stable and more conducive to combustion. The shock wave appears just in the fuel injection vicinity, facilitating the atomization diffusion of the fuel, thereby making the flame more stable. The stable flame heat release forms the combustion chamber back pressure, so that the shock wave is stabilized in the right place. Thus, the shock wave interacts with the flame to achieve a relative balance

\section{Flame extinguishing process}

When the shock-flame balance is broken, the flame cannot be self-sustained by its heat, and tends to extinguish. 


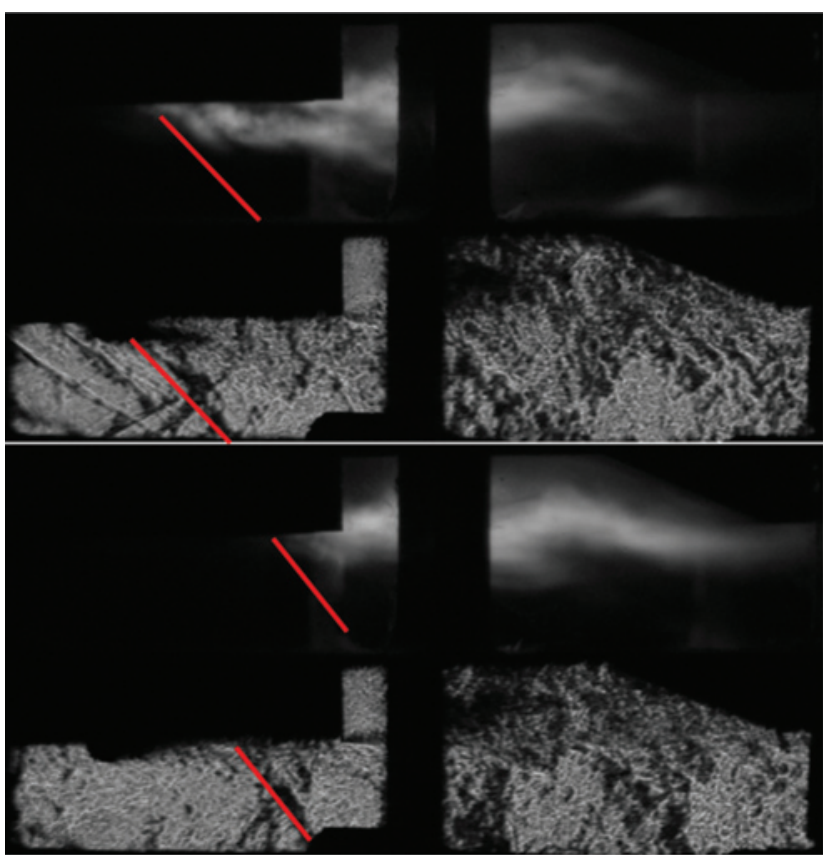

Figure 7: Schlieren image and flame- $\mathrm{CH}^{*}$.

The reasons for breaking the balance may be as follows. First, the flame does not release enough heat at one moment to form a high back pressure shock wave. Second, the increase of or unstable upstream Mach number may push the shock wave downstream as well. Kerosene cracking and heat release become slow in high-speed airflow, and the heat cannot be released in time, so the balance is broken.
In this experiment, we turned off the hydrogen thereby reducing the heat release, and the equilibrium state of heat release back pressure and shock wave was broken. The shock wave cannot be stabilized, and kerosene atomization cannot be promoted, resulting in the flame being extinguished.

It can be seen from Figure 8 that the flameout process is much longer than the ignition process and has undergone repeated iterations. At the moment of extinction, the flame zone is pushed downstream rapidly and shrinking rapidly until all the flames are extinguished. After a number of iterative processes, the flame eventually shrinks and extinguishes at the cavity steps.

To observe the whole combustion process in time, we measured the pressure on the top wall of the first cavity. As shown in Figure 9, in the case of $\Phi=0.20$, the kerosene hadn't been ignited by $\mathrm{H}_{2}$ at first. It has another step at $16 \mathrm{~s}$. It is because a low equivalence ratio is harder to stabilize than a high equivalence ratio.

The pure hydrogen flame sustain time is the time after hydrogen and before kerosene ignition, as shown in Figures 9 and 10. The pure hydrogen flame sustain time is much longer with $\Phi=0.2$ than $\Phi=0.3$ and 0.35 . This is because the low equivalence is harder to stabilize. It seems contrary to the result in "Ignition process" we just said. However, a low equivalence ratio fuel is hard to ignite, but once ignited, it develops fast. Therefore, There exist the long pure hydrogen flame sustain time here and short ignition time in the "Ignition process".

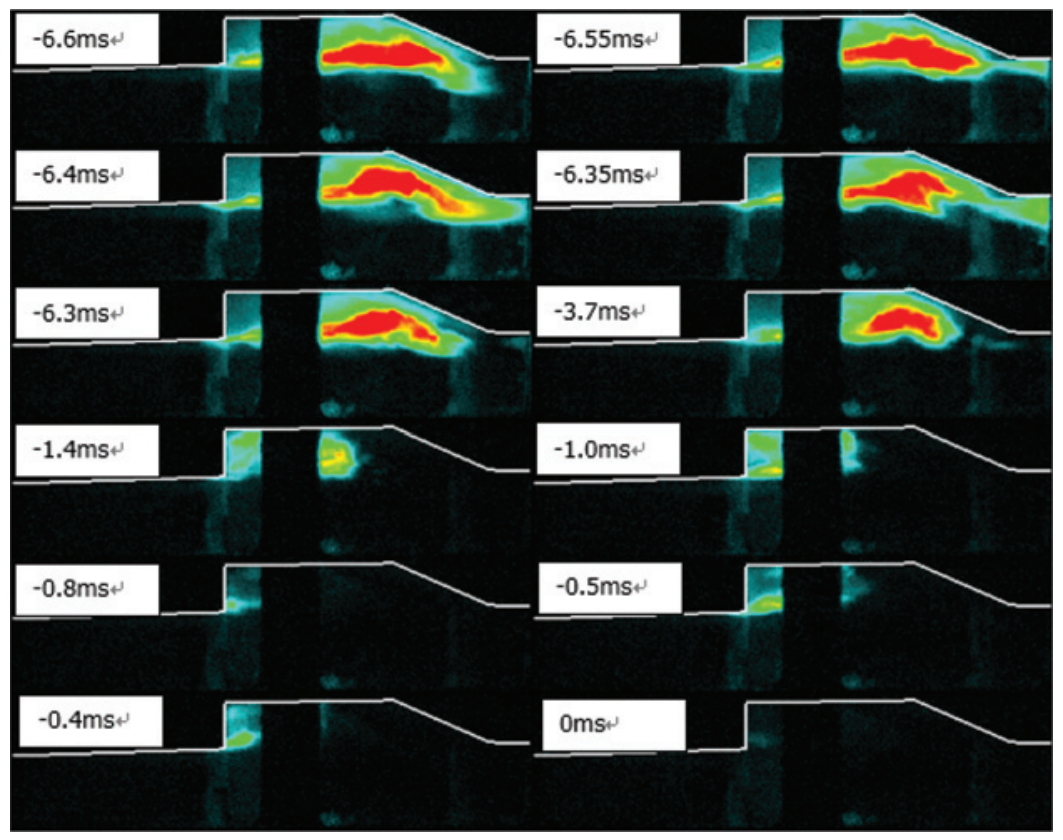

Figure 8: Flame extinguishing process in case R2. 


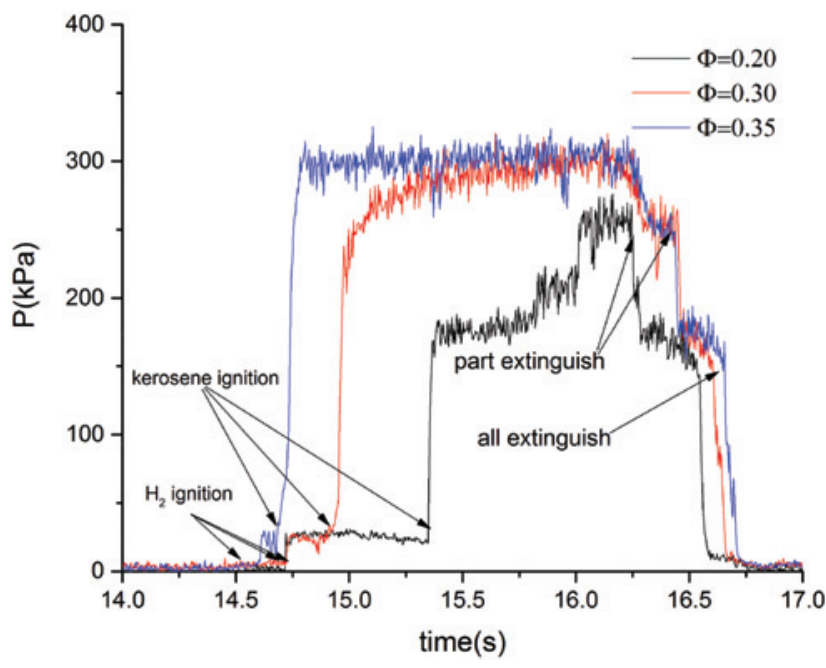

Figure 9: Pressure in the experimental process.

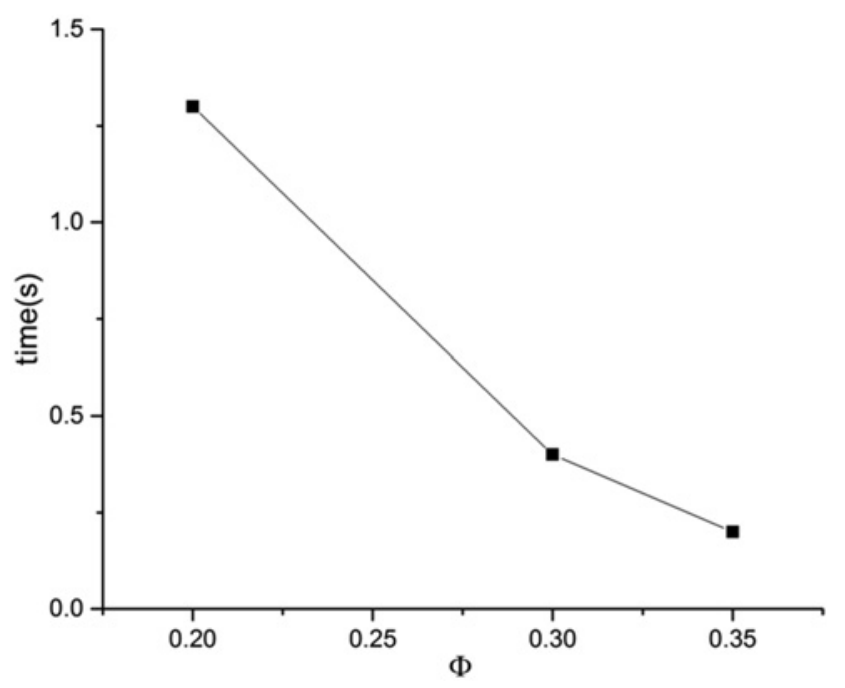

Figure 10: Time of hydrogen fire with equivalence ratio.

\section{Conclusions}

In this study, pilot hydrogen kerosene experiments under different equivalence ratios and Ma 2.5 conditions were carried out. The experiment changed the equivalence ratio of kerosene, and the flame shape evolution of pilot hydrogen and kerosene ignition were described by photographing the $\mathrm{CH}^{\star}$ luminescence. It was found that kerosene ignition spreads backward from the step in different equivalence ratio states, rather than expanding from the spark plug. It is concluded that the fire core expansion time increases with the increase in equivalence ratio.

A stable flame and flameout mechanism was found for supersonic combustion in this experiment. The shock and flame balance each other. In a stable flame state, the shock wave near the kerosene injection hole promotes atomization and blending. The combustion chamber pressure stabilizes the shock wave near the kerosene injection hole, thus forming a stable flame mode. When stability is artificially or accidentally broken, the flame mode changes. The flame is gradually extinguished when the cavity is insufficient to stabilize the flame. The pattern of flame contraction is inverse to flame expansion, but the time is relatively long and is accompanied by repeated attempts to re-ignite. Eventually, the flame shrinks to the position of the cavity step and is extinguished.

This research provides a model of ignition in supersonic flow and reveals the mechanism and characteristics of ignition in supersonic flow compared with previous research on ethylene ignition. Additionally, a shock wave of special significance, which is the flame holder, has been detected. The paper also makes progress in understanding extinguishing, which can be used to reburn or re-ignition of the combustor.

\section{Nomenclature}

$\begin{array}{ll}\text { Ma } & \text {-Mach number } \\ \Phi & \text {-Equivalence ratio } \\ \text { P0 } & \text {-total pressure }(\mathrm{MPa}) \\ \text { T0 } & \text {-total temperature }(\mathrm{K}) \\ \text { Q0 } & \text {-inlet flow rate }(\mathrm{kg} / \mathrm{s})\end{array}$

Acknowledgements: The authors acknowledge the technical assistance provided by the technicians at the Institute of Mechanics, Chinese Academy of Sciences.

Funding: The work is partially supported by National Natural Science Foundation of China (Grant Nos. 11772342).

\section{References}

1. Ben-Yakar A, Hanson RK. Cavity flame-holders for ignition and flame stabilization in scramjets: an overview. J Propul Power. 2001;17:869-77.

2. Liuwei C, Fengquan Z, Zhipu W, Hongbin G, Sugang M, Xinyu Z. Experimental study of ignition and flame characteristics of surrogate of cracked hydrocarbon fuels in supersonic crossflow. In: International Space Planes and Hypersonic Systems and Technologies Conferences, 6-9 March 2017, Xiamen, China.

3. Yu KH, Trouve A, Daily JW. Low-frequency pressure oscillations in a model ramjet combustor. J Fluid Mech. 1991;232:47-72. 
4. Vinogradov V, Grachev V, Petrov M, Sheechman JM. Experimental investigation of 2-D dual mode scramjet with hydrogen fuel at Mach 4-6. AIAA paper, 1990:90-5269.

5. Sun MB, Hong-bo W, Xue-song B, Zhen-guo W, Hui G, Jian-han L, et al. Experimental and numerical study on flame stabilization in a supersonic combustor with hydrogen injection upstream of cavity flameholders. In: 45th AIAA/ASME/SAE/ASEE Joint Propulsion Conference \& Exhibit, 2009:1245-51.

6. Dahms R, Fansler TD, Drake MC, Kuo TW, Lippert AM, Peters N. Modeling ignition phenomena in spray-guided spark-ignited engines. Proc Combust Inst. 2009;21:2734-50.

7. Micka DJ, Driscoll JF. Combustion characteristics of a dualmode scramjet combustor with cavity flameholder. Proc Combust Inst. 2009;32(2):2397-404.

8. Timothy FO, Starkey RP, Lewis MJ. Quasi-one-dimensional high-speed engine model with finite-rate chemistry. J Propul Power. 2001;17(6):1366-74.

9. Daniel James M. Combustion stabilization, structure, and spreading in a laboratory dual-mode scramjet combustor. Doctoral dissertation, University of Michigan, 2010.

10. Huang W, Du ZB, Yan L, Moradi R. Flame propagation and stabilization in dual-mode scramjet combustors: a survey. Prog Aerosp Sci. 2018;101:13-30.

11. Yang $\mathrm{Y}$, Wang Z, Zhang $\mathrm{Y}$, Sun $\mathrm{M}$, Wang H. Flame stabilization with a rear-wall-expansion cavity in a supersonic combustor.
Acta Astronaut. 2018;152:752-6. DOI:10.1016/j. actaastro.2018.09.027.

12. Gruber MR, Baurle RA, Mathur T, Hsu KY. Fundamental studies of cavity-based flameholder concepts for supersonic combustors. J Propul Power. 2001;17:146-53.

13. Cai Z, Sun M, Wang Z, Bai X-S. Effect of cavity geometry on fuel transport and mixing processes in a scramjet combustor. Aerosp Sci Technol. 2018;80:309-14. DOI:10.1016/j. ast.2018.07.028.

14. Tian Y, Yang S, Le J, Su T, Yue M, Zhong F, et al. Investigation of combustion and flame stabilization modes in a hydrogen fueled scramjet combustor. Int J Hydrogen Energy. 2016;41:19218-30. DOI:10.1016/j.ijhydene.2016.07.219.

15. Tian Y, Xiao B, Zhang S, Xing J. Experimental and computational study on combustion performance of a kerosene fueled dual-mode scramjet engine. Aerosp Sci Technol. 2015;46:451-8. DOI:10.1016/j.ast.2015.09.002.

16. Tian Y, Yang S, Le J, Zhong F, Tian X. Investigation of combustion process of a kerosene fueled combustor with air throttling. Combust Flame. 2017;179:74-85. DOI:10.1016/j. combustflame.2017.01.021.

17. Tian Y, Zeng X, Yang S, Zhong F, Le J. Study on the effects of thermal throat on flame stabilization in a kerosene fueled supersonic combustor. Energy Convers Manage. 2018;166:98-105. DOI:10.1016/j.enconman.2018.04.023. 